\title{
Localizar lo internacional, internacionalizar lo local: Unas cuantas experiencias, aprendizajes y reflexiones en torno a los archivos
}

\author{
Localizing the international, internationalizing the local: \\ some experiences, learnings and thoughts on archives
}

\author{
Adriana Minor \\ Doctora en Filosofía \\ de la Ciencia \\ El Colegio de México \\ aminor@colmex.mx
}

Recebido em: 14/04/2020 Aceito em: 20/02/2020

\section{Hacer disponibles las fuentes históricas}

Como muchos historiadores de la ciencia, incursioné en este campo con la ambición de presentar una historia del primer instituto de física que hubo en México, el Instituto de Física de la Universidad Nacional Autónoma de México (IF-UNAM), creado en 1938. Como ocurre muchas veces, el reto fue hacer esta reconstrucción histórica haciendo frente a la inexistencia de un archivo concreto que sirviera directa y evidentemente a los propósitos de la investigación. Esto me lleva a una primera reflexión sobre la dificultad de ocuparse de las historias de las ciencias en contextos donde se valora poco o nada el patrimonio científico. En el caso del IF-UNAM, se dice que en algún momento un alto cargo directivo decidió quemar los "papeles viejos" con el fin de hacer espacio.

Frente a tal clase de situaciones, una alternativa, a veces disponible, es recurrir a archivos de grandes instituciones. El riesgo aquí es que se puede transformar en la búsqueda de una aguja en un pajar, por lo que es importante hacer una selección cuidadosa de este tipo de archivos. En mi caso, acudí entonces al Archivo Histórico de la UNAM, donde me sumergí por varios meses para identificar cualquier documento, de aquí y de allá, que tuviera alguna relación con el IF-UNAM. Aunque por veces desesperante, en retrospectiva creo que resultó ser una experiencia en la que comencé a apreciar la investigación de archivo como una tarea detectivesca y una fuente de sorpresas que aún encuentro inspiradora y motivante.

Sin tener una formación previa como historiadora, sino como física, aprendí sobre la marcha el valor de los instrumentos de búsqueda, la construcción de la fuente, la crítica a los archivos y la sistematización de la información, así como el arduo trabajo de la interpretación histórica, en un intento, siempre difícil, de ir más allá de una simple narración cronológica de los hechos. Un aspecto relevante de la investigación en los archivos sobre el cual vale la pena 
reflexionar aquí, remite a las estrategias de las que disponemos para poder volver a la fuente histórica (se vuelve una y otra vez, más vale tenerlo presente). En aquella primera experiencia de investigación de archivo, acumulé fotocopias de los documentos y confeccioné una base de datos; ahora acumulo fotografías y recientemente he comenzado a utilizar herramientas para la gestión de imágenes de archivo con la plataforma Tropy (una recomendación que, por cierto, recibí de Karin Bugow mientras ambas realizábamos una estancia de investigación en el Rockefeller Archive Center). Asimismo, una opción que he mantenido porque me ha resultado enormemente útil, ha sido la de escribir un diario de investigación donde registro datos básicos de localización de las carpetas que estoy consultando y agrego información del contenido de los documentos que considero relevantes, como nombres, instituciones o temas, así como reflexiones que surgen conforme voy revisando y leyendo el material. $\mathrm{Al}$ fin de cuentas, son distintas formas, en este caso personales, de poner a disposición las fuentes históricas.

\section{Relecturas de las fuentes históricas}

Después de esta experiencia inicial, decidí profesionalizarme como historiadora de la ciencia. Volví, como era de esperarse, sobre las fuentes de archivo que había recabado anteriormente. Aprendí algo quizá muy básico en la formación del historiador, pero sin duda fundamental, que el material de archivo te habla de cosas diferentes dependiendo de las preguntas que le planteas y la perspectiva con que lo leas. Esta vez mis preguntas iban orientadas, no hacia una historia de una institución científica mexicana a través de sus prácticas de investigación, sino a una historia centrada en un instrumento científico, el acelerador Van de Graaff adquirido por esta misma institución en la década de 1950.

Dado que pretendía elaborar un estudio de cultura material de la ciencia, requería considerar otro tipo de fuente histórica además de la escrita, incluso ver el objeto, lo cual me fue posible pues tanto el instrumento como el edificio donde fue instalado aún se preservan, si bien sus usos han cambiado. Desde esa perspectiva, encontré al instrumento no solo en los documentos de archivo o los artículos de investigación publicados por los físicos y los técnicos que trabajaron con él, sino también en fotografías, en un mural, en notas de periódico y en discursos pronunciados con motivo de la construcción del nuevo campus universitario de la UNAM. La evidencia en su conjunto hablaba de sus significados e implicaciones en escalas local, nacional e internacional. Hacer esta reconstrucción histórica tomó rumbos inesperados en los que estas escalas se interrelacionaban.

No es aquí el espacio para detallar esa historia. Simplemente me serviré de un aspecto para ilustrar esta yuxtaposición de diferentes escalas. Para entender por qué se adquirió ese instrumento en particular hay que tomar en cuenta la construcción del nuevo campus de la UNAM al sur de la Ciudad de México, las conexiones que algunos científicos mexicanos mantuvieron con instituciones del área de Boston en Estados Unidos y el contexto internacional de replanteamiento de los usos de la ciencia, en particular de la energía nuclear, lo cual se reflejó en las políticas científicas impulsadas por el gobierno mexicano. Cada uno de estos elementos tiene su propia historia, pero lo que me interesa resaltar es su convergencia en relación a la adquisición del acelerador Van de Graaff.

Un enfoque diferente, con otras preguntas y la apertura suficiente para dejarse llevar por rumbos inesperados, me permitió proponer un análisis que intentaba ir más allá de un marco local, institucional y nacional, aun cuando los archivos que consulté se mantenían justo en ese ámbito. Aun así, las fuentes históricas a las que tuve acceso entonces, eran suficientes para identificar temas como el de las relaciones científicas entre Estados Unidos y México y formular preguntas de investigación que fueron cobrando un protagonismo mayor, esta vez desde otro enfoque.

\section{Seguir las pistas y las conexiones}

Pude profundizar en el tema de las relaciones científicas entre Estados Unidos y México en la primera mitad del siglo XX a través del estudio de la trayectoria de Manuel Sandoval Vallarta como un personaje clave 
en ese sentido. En un inicio, me había planteado como objetivo preparar una biografía de este importante físico mexicano. Obviamente, al investigar aspectos de la historia de la física en México, su nombre había aparecido frecuentemente en el material de archivo que había consultado. Era indiscutible su importancia para la formación de una comunidad de físicos, de una tradición de investigación en física, de instituciones y políticas científicas en México. A pesar de semejante papel, encontraba que buena parte de los trabajos de tipo biográfico mantenían un cierto sesgo hagiográfico. Se repetían los mismos episodios de su vida y se fragmentaba su trayectoria en facetas diferenciadas, especialmente entre lo que atañe a cuestiones de ciencia "propiamente" y de política, por otro lado.

Suerte que Manuel Sandoval Vallarta conservó un rico acervo documental, bibliográfico y gráfico, mismo que tras su muerte fue donado por su esposa a una universidad pública ubicada al oriente de la Ciudad de México. Comencé a sumergirme en este archivo personal (nunca mejor dicho si se tiene en cuenta cuán meticuloso y sistemático fue su artífice), enfocándome en un primer momento en su correspondencia (organizada en científica y personal, aunque muchas veces no era posible distinguir una de la otra). Consulté desde cartas que le enviaron y que envió (conservaba copias de muchas de las cartas que escribió) a físicos galardonados con el Premio Nobel, como Arthur Compton y Albert Einstein, hasta una nota de insultos que alguien le había dejado anónimamente (y donde él mismo había escrito el nombre de un posible autor).

Una serie de cartas resultaron ser especialmente enigmáticas. Fechadas entre 1941 y 1942, parecían referirse a los motivos por los cuales Manuel Sandoval Vallarta había decidido volver a México, después de haberse formado y desempeñado por casi dos décadas como profesor de física en el Massachusetts Institute of Technology (MIT). Sobre su regreso a México se sostenía, él mismo incluso, que había vuelto debido a su compromiso patriótico con el desarrollo de la ciencia. En cambio, las cartas dejaban ver una situación mucho más compleja. Renuncié entonces a los enredos de la biografía, para concentrarme en comprender las razones de su regreso a México y más que eso, la cuestión de quién fue Manuel Sandoval Vallarta en Estados Unidos.

Realicé una estancia de investigación en el MIT con el propósito principal de seguir el rastro de Manuel Sandoval Vallarta en Estados Unidos. Las historias institucionales que encontré allá (no muy diferente de otras que conocía, aunque ciertamente más gloriosas) parecían no dar cabida a actores como él, aunque los documentos del archivo del MIT me hablaban de alguien profundamente implicado con esa institución y que contribuyó muy especialmente a fortalecer la investigación en física teórica. Así noté un desbalance profundo entre el héroe de la ciencia nacional en México y el personaje marginal en Estados Unidos. Concluí que esto se debe, en buena medida, a que aún prevalece, en uno y otro lado, un sesgo hacia los grandes personajes y acontecimientos, dentro de un marco implícita o explícitamente nacional. Con la idea de evitar esta tendencia y tomar en serio el tipo de actor y procesos históricos que se me estaban revelando, recurrí a la aproximación transnacional (y aquí por fin llegamos al motivo principal por el cual fui invitada a participar en esta sección especial), como una forma de interpretar y una metodología de trabajo.

Desde ese enfoque, argumenté que el transnacionalismo de Manuel Sandoval Vallarta fue determinante en su trayectoria. Lo caractericé como un actor transnacional capaz transitar y establecer conexiones entre diferentes contextos culturales, científicos y nacionales. Analicé cómo construyó ese perfil y las circunstancias específicas que le permitieron sacar ventaja de su transnacionalismo, particularmente durante la Segunda Guerra Mundial cuando lideró iniciativas encaminadas a fortalecer las relaciones científicas interamericanas. Asimismo, demostré que fue en esa misma circunstancia de movilización de guerra y de las alineaciones nacionales que eme emergieron rgen en ese contexto, que su transnacionalismo se vio cuestionado, teniendo como desenlace su regreso definitivo a México.

Construí esta interpretación histórica de la trayectoria de Manuel Sandoval Vallarta desde una aproximación transnacional valiéndome, principalmente, de su archivo personal en México y del archivo del MIT, aunque también consulté otros archivos en los cuales identifiqué que podría encontrar pistas que me ayudaran a comprender su papel en el establecimiento de relaciones científicas interamericanas. Recurrí a los archivos de la Carnegie Institution of Washington y la Smithsonian Institution, instituciones que mantuvieron intereses científicos en América Latina. También, busqué en archivos de otras instituciones cientí- 
ficas estadounidenses, que aún sin mantener vínculos directos en América Latina de gran alcance como las anteriores, el asunto fue parte de sus preocupaciones en momentos clave como la Segunda Guerra Mundial, como en el caso de la National Academy of Sciences. La trayectoria de Manuel Sandoval Vallarta también me llevó a poner atención a las medidas implementadas por la Office of the Coordinator of Inter-American Affairs en relación al fortalecimiento de las relaciones científicas interamericanas durante la Segunda Guerra Mundial y cuyos archivos se encuentran en los National Archives and Record Administration. El archivo de la Unesco fue relevante para comprender la continuidad de las relaciones científicas interamericanas a través de los mecanismos de cooperación científica impulsados por los organismos internacionales en la posguerra. Consultar todos estos archivos (que me fue posible gracias a varias becas que solicité) con la atención puesta en las conexiones científicas transnacionales, abrió mi panorama de investigación a otros temas.

\section{Límites a la perspectiva transnacional}

Entre estos temas, el estudio de los rayos cósmicos en América Latina me pareció sumamente interesante por varias razones. Involucra tomar en cuenta diferentes estrategias y espacios de investigación, tales como la organización y ejecución de expediciones científicas y el establecimiento de estaciones de investigación en América Latina. De manera semejante al caso del acelerador Van de Graaff, en el estudio de los rayos cósmicos se yuxtaponen diferentes escalas de análisis y la movilización de objetos, personas y prácticas. Además, este tema de investigación remite a la creación de instituciones pioneras en la investigación en física en varios países de la región. En este caso también es crucial atender a la conformación de relaciones científicas interamericanas y a cuestiones de historia diplomática en momentos de transición sobre el papel de la ciencia en asuntos de política exterior.

Para el desarrollo de este proyecto, he retomado una parte del material de archivo que he acumulado con el tiempo. En algunos casos, inclusive regresé a algunos archivos que había consultado anteriormente, esta vez buscando trazas históricas de los rayos cósmicos. A este repertorio he agregado algunos archivos en Brasil (gracias a una beca posdoctoral concedida por CAPES) y el archivo de la Rockefeller Foundation (gracias a una beca concedida por el Rockefeller Archive Center). Dado que esta historia se desenvuelve a través de varios países de América Latina, tales como Argentina, Bolivia, Brasil, Chile, México, Panamá y Perú, aún me pregunto si, para lograr una imagen lo más completa posible y hacer esta investigación con una rigurosidad acorde con la perspectiva transnacional, además debiera consultar archivos en todos estos países. Esto no es evidente por cuestiones de financiamiento, tiempo y disponibilidad de acervos históricos relacionados más o menos directamente con este tema de investigación. Otra inquietud a la que me enfrento tiene que ver con la perspectiva espacial que me parece un enfoque relevante para el caso, ¿será que, de manera semejante a lo que se aprende con el estudio de la cultura material, la experiencia del espacio mediante la visita a alguna de las estaciones de investigación de rayos cósmicos, localizadas en montañas elevadas de la región, aportaría una comprensión histórica mayor y específica sobre esos espacios de conocimiento? Si el espacio es mucho más que un simple escenario, ¿cómo tomarlo en serio como elemento de análisis?

Quizá el desafío en este caso consiste en saber hacer con lo que se dispone, en vez de esperar hasta abarcarlo todo. No siempre es posible darse el lujo de seguir las pistas de nuestros objetos de estudio. Los límites a la investigación en perspectiva transnacional se imponen con el acceso a becas u otras formas de financiamiento, el tiempo disponible para desarrollar una investigación, el acceso a ciertos archivos y a otros no, además del dominio de diferentes lenguas, lo cual muchas veces es determinante. Si consideramos la valoración que se hace de las historias que escribimos en relación a las tendencias actuales en la profesión, quizá este tipo de dificultades colocan a muchos historiadores en una situación de desventaja. Al mismo tiempo, hay historias de tipo transnacional o global que se construyen sin salir de Ginebra, por ejemplo. Esto demuestra que si el enfoque y las preguntas de investigación son las adecuadas, entonces se pueden desenvolver esas perspectivas con los archivos que se tienen al alcance. 


\section{¿Qué hace "internacional" a un archivo?}

Hay archivos que se consideran internacionales simplemente porque concentran los documentos producidos por organismos internacionales, muchos con sede en Ginebra y otras grandes ciudades como Nueva York, París y Viena. Un archivo como el de la Rockefeller Foundation es “internacional” por el alcance y los objetivos que históricamente se planteó esta institución (aunque para algunos historiadores se trate de un internacionalismo nacionalista). También, influye la proyección de este archivo, que se refuerza con las becas que ofrece y que permiten que sea un lugar de encuentro de historiadores de muchas partes del mundo. Evidentemente, pocos archivos cuentan con los recursos necesarios para volverse internacionales por esa vía.

Habría que considerar otras estrategias que permitan internacionalizar archivos que pocas veces tienen una proyección más allá de lo local y nacional. Una estrategia posible que se inspira en el hecho de que las preguntas con las que llegamos a los archivos son determinantes para hacer notar su lado "internacional", consiste en vincular archivos alrededor de una pregunta y una perspectiva, como la que motiva este número especial sobre actores científicos transnacionales. Así quizá se podrían buscar plataformas que permitan enlazar virtualmente los archivos personales de Manuel Sandoval Vallarta y Guido Beck, por poner un ejemplo. Idear estrategias que permitan vincular archivos localizados en diferentes países, como en este ejemplo, sería otra forma de potenciar su alcance "internacional". 